\title{
TM4SF1 inhibits apoptosis and promotes proliferation, migration and invasion in human gastric cancer cells
}

\author{
YUNHAI WEI ${ }^{1}$, XIAOYING SHEN $^{1}$, LIQIN LI $^{1}$, GUOLIANG CAO $^{1}$, XUHUA CAI $^{2}$, YAN WANG $^{1}$ and HUA SHEN ${ }^{1}$ \\ Departments of ${ }^{1}$ Gastrointestinal Surgery and ${ }^{2}$ Digestion, Huzhou Central Hospital, Huzhou, Zhejiang 313000, P.R. China
}

Received December 29, 2017; Accepted June 26, 2018

DOI: $10.3892 / \mathrm{ol} .2018 .9411$

\begin{abstract}
Gastric cancer (GC) is associated with poor patient prognosis, and so it crucial to investigate the molecular mechanisms underlying the progression of GC. The aim of the present study was to investigate the role of transmembrane-4 L6 family member 1 (TM4SF1) in the progression of GC. TM4SF1 small interfering RNA (siRNA) and TM4SF1-expressing plasmids were employed to regulate TM4SF1 expression. In vitro experiments were performed to determine the effect of TM4SF1 on the expression of apoptosis-associated molecules and determine the role of TM4SF1 in apoptosis, proliferation, migration and invasion using human GC cell lines MGC803 and MKN45. The data of the present study demonstrated that TM4SF1 may regulate the expression of apoptosis-associated molecules at the mRNA and protein levels. TM4SF1 silencing reduced B-cell lymphoma 2 ( $\mathrm{Bcl} 2$ ) expression, whilst caspase-3 and $\mathrm{Bcl} 2$-associated $\mathrm{X}$ expression increased, and upregulating TM4SF1 reversed these changes in GC cells. Furthermore, TM4SF1 knockdown promoted apoptosis while inhibiting the proliferation, migration and invasion of GC cells. Rescue experiments demonstrated that TM4SF1 upregulation reversed the changes induced by transfection with TM4SF1 siRNA. In summary, TM4SF1 is an anti-apoptosis protein associated with the progression of GC. Additional in vivo experiments and clinical trials are required to confirm the possible use of TM4SF1 in tumor therapy.
\end{abstract}

Correspondence to: Dr Yunhai Wei, Department of Gastrointestinal Surgery, Huzhou Central Hospital, 198 Hongqi Road, Huzhou, Zhejiang 313000, P.R. China

E-mail: yunhaiwei@126.com

Abbreviations: GC, gastric cancer; VEGF, vascular endothelial growth factor; RT-qPCR, reverse transcription-quantitative polymerase chain reaction; PVDF, polyvinylidene fluoride

Key words: transmembrane-4 L6 family member 1, progression, anti-apoptosis, tumor therapy, gastric cancer

\section{Introduction}

Gastric cancer (GC) is a disease that poses a serious threat to human health and quality of life globally (1). In 2015, GC is the third highest cause of cancer-associated moralities in males and the second highest in females in China (2). Currently, patients with GC generally have a poor prognosis, and early diagnosis is important to improve patient outcomes (3). Treatment primarily comprises of combined therapy of surgery with chemotherapy and radiotherapy; however, this treatment regime has limited effectiveness. Due to the majority of patients with GC being diagnosed at advanced stages, the resection rate for $\mathrm{GC}$ has been reported to be $\sim 50 \%$ (4). Chemotherapy is an adjunctive treatment that is only able to alleviate the symptoms and prolong the survival of patients with GC, rather than treating the disease (5). Whether adjuvant radiotherapy can improve the overall survival of patients with GC remains controversial (6). Developing effective therapeutic strategies based on novel targets may help to improve the overall prognosis of patients with GC. Investigating the molecular mechanisms underlying GC progression is crucial in the identification of novel therapeutic targets.

Transmembrane-4 L6 family member 1 (TM4SF1), a low molecular weight protein consisting of 202 amino acids, is a member of the transmembrane-4 protein L6 superfamily. This family also includes TM4SF4, TM4SF5 and TM4SF18 (7). TM4SF1 is highly expressed in activated endothelial cells and can activate vascular endothelial growth factor (VEGF)-A or thrombin to stimulate angiogenesis (8). Additionally, TM4SF1 may also promote cell migration by increasing the formation of filopodia (9). TM4SF1 may therefore be a tumor promoter, and a number of studies have confirmed the important role of TM4SF1 in tumor progression. Cao et al (10) reported that TM4SF1 regulates pancreatic cancer migration and invasion in vitro and in vivo. Huang et al (11) reported that TM4SF1 promotes proliferation, invasion and metastasis in human liver cancer cells. Sun et al (12) confirmed that TM4SF1 regulates breast cancer cell migration and apoptosis; however, the effects of TM4SF1 on GC remain unclear.

A previous study reported that TM4SF1 was overexpressed in GC (13). Based on this, it was hypothesized in the present study that TM4SF1 may be an important regulator of GC development. The aim of the present study was to assess the effects of TM4SF1 on the proliferation, migration and invasion of GC cells. These data may improve the understanding of the 
molecular mechanisms underlying GC progression, providing a basis for the development of effective therapeutic strategies.

\section{Materials and methods}

Cell culture and reagents. Human GC cell lines MGC803 and MKN45 were obtained from the Cell Bank of the Shanghai Institute of Biological Sciences, Chinese Academy of Sciences (Shanghai, China) and maintained in RPMI-1640 supplemented with $10 \%$ fetal bovine serum (FBS; Gibco; Thermo Fisher Scientific, Inc., Waltham, MA, USA) and $1 \%$ penicillin/streptomycin at $37^{\circ} \mathrm{C}$ in a humidified atmosphere containing $5 \%$ $\mathrm{CO}_{2}$. Antibodies against B-cell lymphoma 2 (Bcl2; 1:500; ab692), caspase-3 (1:1,000; ab13847), Bcl2-associated X (Bax; 1:2,000; ab32503) and $\beta$-actin $(1: 2,000 ; a b 8227)$ were purchased from Abcam (Cambridge, UK). Bound antibodies were detected with horseradish peroxidase-conjugated antibody against mouse $(1: 10,000 ;$ ab6728; Abcam) or rabbit IgG (1:10,000; sc-2357; Santa Cruz Biotechnology, Inc., Dallas, TX, USA), followed by enhanced chemiluminescence detection (GE Healthcare Life Sciences, Little Chalfont, UK).

Gene transduction. The TM4SF1 small interfering RNA (siRNA), TM4SF1-expressing plasmid and their control vectors were obtained from Shanghai GenePharma Co., Ltd. (Shanghai, China). The sequence of TM4SF1 siRNA was as follows: Sense, 5'-GGCUCUUGGUCGGAAUUGAATT-3', and antisense, 5'-UUCAAUUCCACCAAGAGCCTT-3'. The TM4SF1-expressing plasmid was constructed by subcloning the human TM4SF1 cDNA by Shanghai GenePharma Co., Ltd.. MGC803 and MKN45 cells were seeded on to a 24-well plate at a concentration of $1 \times 10^{5}$ cells/well for transfection. TM4SF1 siRNA (50 $\mathrm{nM}$ ) and TM4SF1-expressing plasmid $(1 \mu \mathrm{g} /$ well) were transfected into MGC803 and MKN45 cells with Lipofectamine ${ }^{\circledR} 2000$ (Invitrogen; Thermo Fisher Scientific, Inc.), according to the manufacturer's protocol. The control group represented MGC803 and MKN45 cells transfected with their control vectors. The siTM4SF1 group represented MGC803 and MKN45 cells transfected with TM4SF1 siRNA. The specificity of TM4SF1 siRNA was verified by a rescue experiment (14). In the rescue experiment, the TM4SF1 siRNA and TM4SF1-expressing plasmid were co-transfected into MGC803 and MKN45 cells, denoted as the siTM4SF1+TM4SF1 group. Changes in TM4SF1 expression levels were assessed using reverse transcription-quantitative polymerase chain reaction (RT-qPCR) at $48 \mathrm{~h}$ after transfection.

$R T$ - $q P C R$. Total RNA was isolated from MGC803 and MKN45 cells using TRIzol ${ }^{\oplus}$ (Invitrogen; Thermo Fisher Scientific, Inc.). Purified RNA was reverse transcribed into cDNA with the M-MLV First Strand kit (Invitrogen; Thermo Fisher Scientific, Inc.), according to the manufacturer's protocol. RT-qPCR reactions were conducted using the $\mathrm{SYBR}^{\circledast}$ mix (Invitrogen; Thermo Fisher Scientific, Inc.) on an ABI PRISM 7500 Sequence Detection system (Applied Biosystems; Thermo Fisher Scientific, Inc.) (15). Briefly, after an initial denaturation step at $95^{\circ} \mathrm{C}$ for $30 \mathrm{sec}$, amplifications were conducted with 40 cycles of $95^{\circ} \mathrm{C}$ for $5 \mathrm{sec}$ and $60^{\circ} \mathrm{C}$ for $34 \mathrm{sec}$. Human $\beta$-actin was used as the housekeeping gene to normalize the expression levels of the target genes $(16,17)$. Primers used were as follows: TM4SF1, forward, 5'-CTGCTCTCACCAACAGCA AT-3', and reverse, 5'-TGCCAGTCTTTACAGGCGTT-3'; Bcl2, forward, 5'-CAGGAAACGGCCCGGAT-3', and reverse, 5'-CTGGGGCCTTTCATCCTCC-3'; Bax, forward, 5'-GGG TTGTCGCCCTTTTCTAC-3', and reverse, 5'-CTGGAGACA GGGACATCAGT-3'; caspase-3, forward, 5'-TGCTATTGT GAGGCGGTTGTAG-3', and reverse, 5'-GGCACACCCACC GAAAAC-3'; and $\beta$-actin, forward, 5'-CATTAAGGAGAA GCTGTGCT-3', and reverse, 5'-GTTGAAGGTAGTTTCGTG GA-3'. The relative expression levels were quantified with the $2^{-\Delta \Delta C q}$ method (18).

Western blotting. The protein was extracted from cells using a mixture of Pierce RAPI Buffer (Thermo Fisher Scientific, Inc.) and Halt Protease Inhibitor Cocktail (Thermo Fisher Scientific, Inc.) at a ratio of 100:1. The protein concentration was determined using the bicinchoninic acid assay (Thermo Fisher Scientific, Inc.). Lysates of MGC803 and MKN45 cells were centrifuged at $4^{\circ} \mathrm{C}$ for $10 \mathrm{~min}$ at $12,000 \mathrm{x} \mathrm{g}$. Equal amounts of proteins $(50 \mu \mathrm{g})$ were separated by $10 \%$ SDS-PAGE and transferred onto polyvinylidene fluoride membranes. Following blocking with $5 \%$ bovine serum albumin (Invitrogen; Thermo Fisher Scientific, Inc.)/PBS with Tween 20 buffer at $37^{\circ} \mathrm{C}$ for $1 \mathrm{~h}$, membranes were incubated with primary antibodies at $4^{\circ} \mathrm{C}$ overnight. Subsequently, blots were incubated with horseradish peroxidase-linked secondary antibodies at $37^{\circ} \mathrm{C}$ for $2-3 \mathrm{~h}$. Immunoreactive proteins were detected using the SuperSignal West Pico Chemiluminescent substrate (Thermo Fisher Scientific, Inc.). Bands were quantified using ImageJ 1.50i (National Institutes of Health, Bethesda, MD, USA) (19).

Cell apoptosis assay. Apoptosis of MGC803 and MKN45 cells was evaluated using flow cytometry with an Annexin V-fluorescein isothiocyanate (FITC)/propidium iodide (PI) Apoptosis kit (BD Pharmingen; BD Biosciences, Franklin Lakes, NJ, USA), according to the manufacturer's protocol. Cells were washed with cold PBS twice and resuspended in $100 \mu \mathrm{l} 1 \mathrm{X}$ binding buffer, following which $5 \mu \mathrm{l}$ Annexin V-FITC and $5 \mu \mathrm{l}$ PI were added for $10 \mathrm{~min}$ at room temperature in the dark. Finally, $400 \mu \mathrm{l}$ binding buffer was added to the cells, which were analyzed by a flow cytometer. All data were analyzed by FlowJo software version 7.6.1 (FlowJo LLC, Ashland, OR, USA).

Proliferation assay. An MTT assay was used to measure the viability of MGC803 and MKN45 cells. A $100 \mu \mathrm{l}$ GC cell suspension containing 2,000 cells was seeded in each well of a 96-well plate and incubated for $4 \mathrm{~h}$ in an atmosphere containing $5 \% \mathrm{CO}_{2}$ at $37^{\circ} \mathrm{C}$. Subsequently, $100 \mu \mathrm{l}$ MTT solution was added to each well and incubated for $4 \mathrm{~h}$ in an atmosphere containing $5 \% \mathrm{CO}_{2}$ at $37^{\circ} \mathrm{C}$. A total of $100 \mu \mathrm{l}$ dimethyl sulfoxide was added to each well and incubated again for $4 \mathrm{~h}$ in an atmosphere containing $5 \% \mathrm{CO}_{2}$ at $37^{\circ} \mathrm{C}$, in order to dissolve the formazan crystals. Absorbance was measured at $570 \mathrm{~nm}$ using a Multiskan Plate Reader (Thermo Fisher Scientific, Inc.). Each experiment was repeated three times.

Transwell assay. Cell migration ability was measured using cell culture inserts (24-well type, $8-\mu \mathrm{m}$ pore size; 

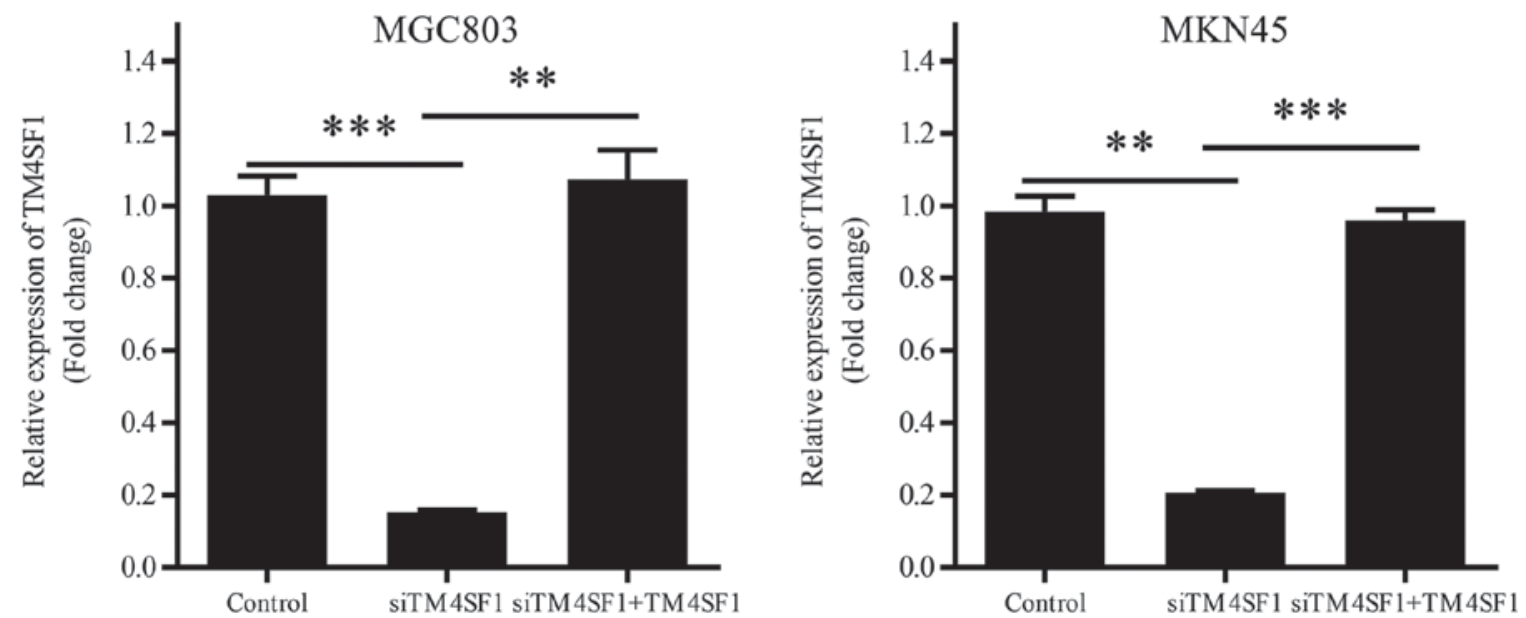

Figure 1. Efficiency of TM4SF1 siRNA and the TM4SF1-expressing plasmid. Cell lines MGC803 and MKN45 were transfected with blank vectors, TM4SF1 siRNA or TM4SF1 siRNA and the TM4SF1-expressing plasmid. TM4SF1 expression was measured using reverse transcription-quantitative polymerase chain reaction and expressed as fold-change. Each column is presented as the mean of three separate experiments. ${ }^{* *} \mathrm{P}<0.01$ and ${ }^{* * * *} \mathrm{P}<0.001$. siRNA, small interfering RNA; TM4SF1, transmembrane-4 L6 family member 1; siTM4SF1, cells transfected with TM4SF1 siRNA; control, cells transfected with blank vectors; siTM4SF1+TM4SF1, cells transfected with TM4SF1 siRNA and the TM4SF1-expressing plasmid.

Corning Incorporated, Corning, NY, USA). Subsequently, $1 \times 10^{5}$ MGC803 and MKN45 cells were added into the upper chambers with serum-free RPMI-1640 medium, while the lower chambers were filled with $500 \mu 1$ RPMI-1640 supplemented with $10 \%$ FBS. Following $16 \mathrm{~h}$ of incubation at $37^{\circ} \mathrm{C}$, the cells that had migrated to the lower chamber were fixed in $100 \%$ methanol at room temperature for $30 \mathrm{~min}$ and stained with $0.1 \%$ crystal violet at room temperature for $20 \mathrm{~min}$. Cells were visualized and the number in 10 random fields were counted under a light microscope (Olympus Corporation, Tokyo, Japan; magnification, $\mathrm{x} 400$ ).

Wound-healing assay. MGC803 and MKN45 cells were seeded in 6-well plates ( $5 \times 10^{5}$ cells/well) with $2 \mathrm{ml} \mathrm{RPMI}-1640$ medium supplemented with $10 \%$ FBS. Once $80 \%$ confluence was attained, scratches were produced using a 100- $\mu 1$ pipette tip. Wound healing was observed and images of the migration distance were captured at room temperature at 0 and $24 \mathrm{~h}$ under a light microscope (Olympus Corporation; magnification, $\mathrm{x} 100$ ).

Statistical analysis. Statistical analysis was performed using SPSS v21.0 (IBM Corp., Armonk, NY, USA) and GraphPad Prism v5.0 (GraphPad Software, Inc., La Jolla, CA, USA) software. Differences between $\geq 2$ groups were assessed using one-way analysis of variance followed by Tukey's post-hoc test. Data are presented as the mean \pm standard error of the mean. All experiments comprised three replicates and were performed at least twice independently. $\mathrm{P}<0.05$ was considered to indicate a statistically significant difference, unless otherwise stated.

\section{Results}

Efficiency of TM4SF1 siRNA and TM4SF1-expressing plasmid. The efficiency of gene transduction was confirmed by RT-qPCR. The results for MGC803 and MKN45 were consistent with one another. TM4SF1 mRNA expression was significantly downregulated in the siTM4SF1 group, compared with the control group $(\mathrm{P}<0.001$ and $\mathrm{P}<0.01$, respectively; Fig. 1). Transfection with the TM4SF1-expressing plasmid was demonstrated to significantly reversed the reduction of TM4SF1 mRNA expression, compared with the siTM4SF1 group $(\mathrm{P}<0.01$ and $\mathrm{P}<0.001$, respectively; Fig. 1).

TM4SF1 influences the expression of apoptotic molecules in MGC803 and MKN45 cells. The expression of apoptotic molecules was assessed using RT-qPCR. By comparing the siTM4SF1 group with the control group, it was demonstrated that TM4SF1 silencing significantly decreased Bcl2 mRNA expression, whilst caspase- 3 and Bax expression levels were upregulated $(\mathrm{P}<0.001$; Fig. 2A). By comparing the siTM4SF1 and siTM4SF1+TM4SF1 groups, it was demonstrated that TM4SF1 upregulation significantly reversed alterations in the mRNA expressions profile of MGC803 and MKN45 cells $(\mathrm{P}<0.001$; Fig. 2A). Western blotting was used to assess these genes at the protein level. The results indicated that the effects of TM4SF1 on Bcl2, caspase- 3 and Bax protein expression levels were consistent with the mRNA expression level results, and the comparison was statistically significant $(\mathrm{P}<0.05$; Fig. $2 \mathrm{~B})$. Flow cytometry was used to verify the role of TM4SF1 in the apoptosis of MGC803 and MKN45 cells. The results demonstrated that the apoptosis of MGC803 and MKN45 cells in the siTM4SF1 group was significantly promoted, compared with the control group $(\mathrm{P}<0.01$ and $\mathrm{P}<0.05$, respectively; Fig. 3). Rescue experiments demonstrated that the apoptosis of MGC803 and MKN45 cells in the siTM4SF1+TM4SF1 group was significantly decreased, compared with the siTM4SF1 group $(\mathrm{P}<0.05$ and $\mathrm{P}<0.01$, respectively; Fig. 3). These results were consistent with changes in the expression of the aforementioned apoptotic molecules.

Roles of TM4SF1 in the proliferation, migration and invasion of MGC803 and MKN45 cells. To investigate the biological functions of TM4SF1 in GC, the proliferation, invasion and migration of MGC803 and MKN45 cells were assessed 

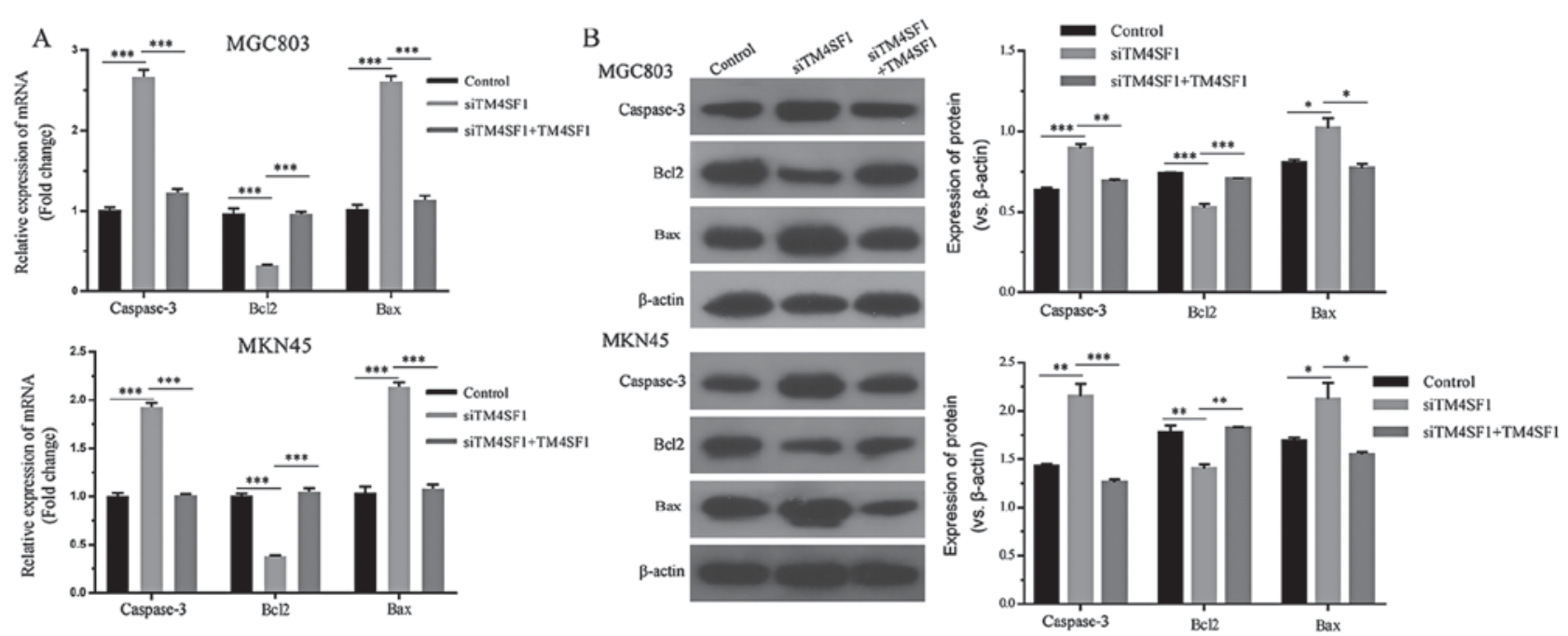

Figure 2. TM4SF1 influences the expression of apoptotic molecules in gastric cancer cells. (A) TM4SF1 silencing decreased the expression of Bcl2 mRNA and upregulated caspase-3 and Bax mRNA. Upregulating TM4SF1 reversed these effects. (B) Values represent fold-change compared with $\beta$-actin. Silencing the TM4SF1 gene decreased Bcl2 protein expression, and increased caspase-3 and Bax protein expression. Upregulating TM4SF1 reversed these changes. Each column is presented as the mean of three separate experiments. " $\mathrm{P}<0.05,{ }^{* *} \mathrm{P}<0.01$ and ${ }^{* * *} \mathrm{P}<0.001$. Bcl2, B-cell lymphoma 2; Bax, Bcl2-associated X; TM4SF1, transmembrane-4 L6 family member 1; siTM4SF1, cells transfected with TM4SF1 siRNA; control, cells transfected with blank vectors; siTM4SF1+TM4SF1, cells transfected with TM4SF1 siRNA and the TM4SF1-expressing plasmid.

following the manipulation of TM4SF1 expression. The proliferation of MGC803 and MKN45 cells was measured using an MTT assay. Wound healing assays were used to measure the invasion of MGC803 and MKN45 cells. Transwell assays were used to measure the migration ability of MGC803 and MKN45 cells. The results demonstrated that TM4SF1 knockdown significantly reduced the proliferation of MGC803 and MKN45 cells, compared with the control group $(\mathrm{P}<0.05$, and $\mathrm{P}<0.05$, respectively; Fig. 4A), while TM4SF1 upregulation significantly increased the proliferation of MGC803 and MKN45 cells, compared with the siTM4SF1 group $(\mathrm{P}<0.05$ and $\mathrm{P}<0.01$, respectively; Fig. 4A). TM4SF1 knockdown significantly reduced the invasion of MGC803 and MKN45 cells, compared with the control group $(\mathrm{P}<0.05$ and $\mathrm{P}<0.05$, respectively; Fig. 4B), while TM4SF1 upregulation significantly increased the invasion of MGC803 and MKN45 cells, compared with the siTM4SF1 group $(\mathrm{P}<0.01$ and $\mathrm{P}<0.001$, respectively; Fig. 4B). TM4SF1 knockdown resulted in significantly reduced migration of MGC803 and MKN45 cells, compared with the control group $(\mathrm{P}<0.001$ and $\mathrm{P}<0.05$, respectively; Fig. $4 \mathrm{C})$, while TM4SF1 upregulation significantly increased migration of MGC803 and MKN45 cells, compared with the siTM4SF1 group $(\mathrm{P}<0.001$ and $\mathrm{P}<0.01$, respectively; Fig. $4 \mathrm{C})$.

\section{Discussion}

A number of studies have indicated that TM4SF1 may inhibit tumor apoptosis and promote tumor proliferation (10-12); however, the underlying mechanisms are notably complex. Sun et al (12) reported that the phosphoinositide 3-kinase (PI3K)/AKT/mechanistic target of rapamycin (mTOR) signaling pathway served a role in TM4SF1 regulation in breast cancer cell apoptosis. The PI3K/AKT/mTOR signaling pathway has been reported to regulate apoptosis in a number of tumor types, including breast cancer, glioma and nasopharyngeal cancer (20-22). The anti-apoptotic effects of the
PI3K/AKT/mTOR signaling pathway are dependent upon downstream apoptosis-associated proteins, including $\mathrm{Bcl} 2$, Bax and caspase-3 (23). Bcl2, as a member of the Bcl2 family, can prevent the release of cytochrome $c$ from the mitochondria to the cytoplasm, thereby inhibiting apoptosis (24). The Bcl2 family is comprised of polarized groups of proteins containing pro-apoptotic proteins and anti-apoptotic proteins, and cell survival or apoptosis depend on the balance between these two types (25). Bax, a pro-apoptotic protein belonging to the Bcl2 family, can form a heterodimer with Bcl2 to inhibit its function (24). Caspase-3 is the most critical apoptotic protease involved in apoptosis. DNA-dependent protein kinase and poly adenosine diphosphate ribose polymerase are important DNA repair enzymes. Caspase-3 can hydrolysate these two enzymes to prevent DNA replication, transcription and injury repair (26). The results of the present study demonstrated that siTM4SF1 upregulates the expression of pro-apoptosis proteins Bax and caspase-3 and downregulates the expression of anti-apoptosis protein $\mathrm{Bcl} 2$. This indicates that TM4SF1 may serve as an anti-apoptotic protein in GC.

The results of the present study demonstrated the important role of TM4SF1 in tumor migration and invasion, and the complex mechanisms underlying has been verified in previous studies (27-29). Lekishvili et al (27) reported that TM4SF1 may be associated with tetraspanin-enriched microdomains, which are crucial for the pro-migratory activity of membrane proteins; furthermore, TM4SF1 overexpression downregulated the expression of tetraspanins cluster of differentiation (CD)63 and CD82, which are associated with the regulation of surface $(28,29)$. CD82 can promote the proliferation of epidermal growth factor receptor to activate signaling cascades, including the FAK-Lyn-p130CAS-CrkII signaling pathway, which results in reduced cell motility (30). A number of additional molecules are associated with TM4SF1. A previous study demonstrated revealed an association between TM4SF1 

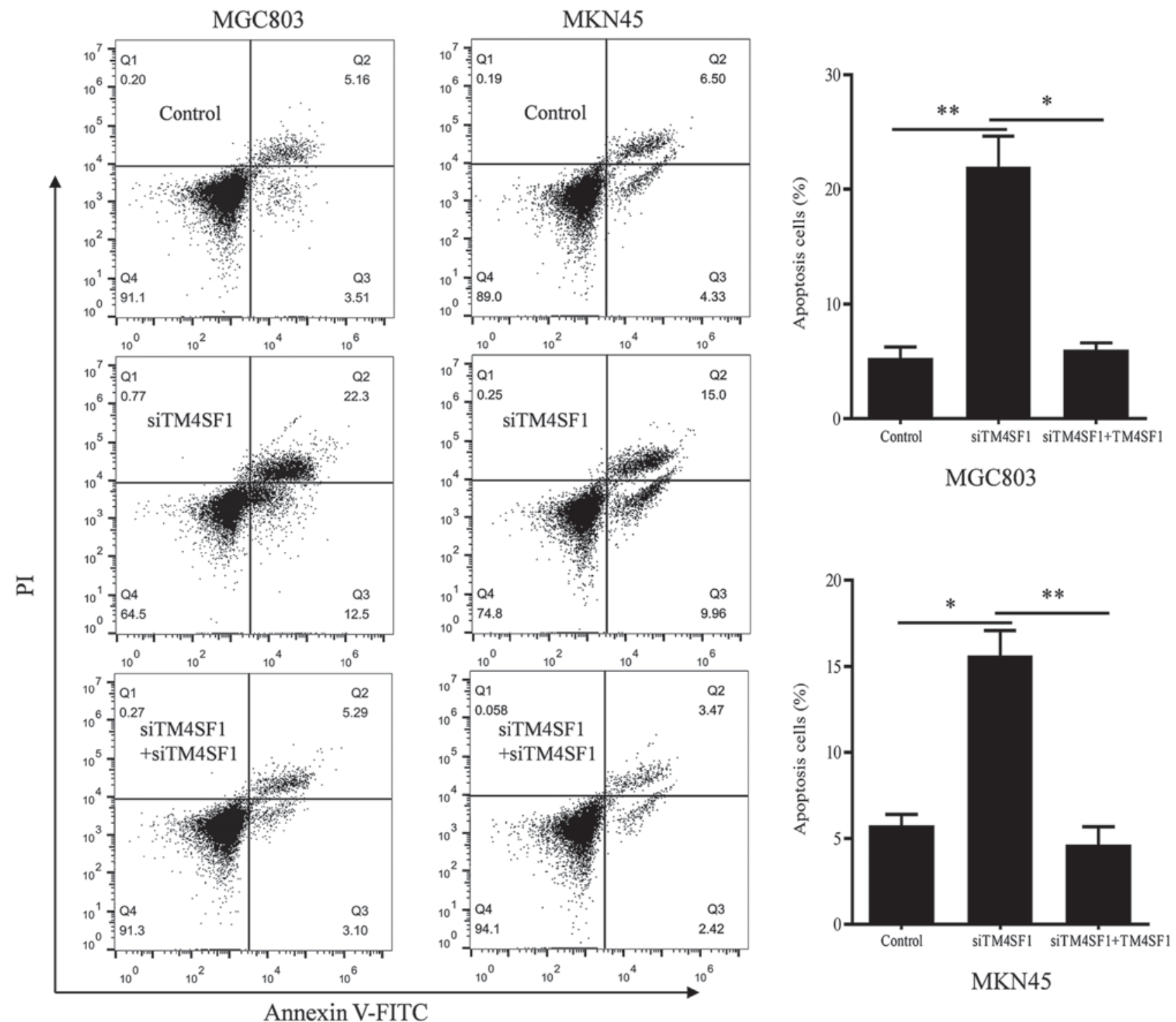

MKN45

Figure 3. The role of TM4SF1 in gastric cancer cell apoptosis. Apoptosis was assessed using flow cytometry and representative images are depicted. Each column is presented as the means of three separate experiments. ${ }^{\prime} \mathrm{P}<0.05,{ }^{* * *} \mathrm{P}<0.01$. PI, propidium iodide; FITC, fluorescein isothiocyanate; TM4SF1, transmembrane-4 L6 family member 1; siTM4SF1, cells transfected with TM4SF1 siRNA; control, cells transfected with blank vectors; siTM4SF1+TM4SF1, cells transfected with TM4SF1 siRNA and the TM4SF1-expressing plasmid.

and CD13 using coimmunoprecipitation analysis, which can form and enhance cell migration in lung cancer cells (31). In prostate cancer, TM4SF1 was reported to directly target the androgen receptor to promote cell migration (32).

In the present study, functional experiments were performed to verify the effects of TM4SF1 knockdown and upregulation in GC cells. The results demonstrated that TM4SF1 may regulate the apoptosis, proliferation, migration and invasion of $\mathrm{GC}$ cells; however, tumor progression is a complicated process with numerous contributing factors, relying on not only the changes in tumor cells but also changes in the tumor microenvironment (33). It is therefore necessary to investigate the role of TM4SF1 in the tumor microenvironment.

Xue et al (34) demonstrated that matrix metallopeptidase (MMP)-2, MMP-9 and VEGF are the downstream proteins of TM4SF1, and TM4SF1 overexpression in turn upregulated MMP-2, MMP-9 and VEGF expression. VEGF is known to be a strong angiogenic factor, and the binding of VEGF and its receptors may stimulate endothelial cell division, proliferation and migration, promote physiological and pathological neovascularization, increase microvascular permeability and promote embryonic hematopoiesis (35-37). VEGF overexpression promotes the secretion of MMP-2 and MMP-9, which may serve a crucial role in tumor invasion and metastasis $(28,29)$. MMP-2, a zinc-dependent proteolytic enzyme that is secreted by tumor and stromal cells in the form of zymogens, has been reported to be closely associated with the development of tumors. Following hydrolysis, MMP-2 promotes the transformation of the extracellular matrix by degrading the main constituents of the basement membrane, including type IV, V, VI and X collagens and gelatin. This promotes tumor neovascularization, invasion and metastasis (38). MMP-9 is the enzyme with the largest molecular weight in the MMP family, and is also secreted in zymogen form. Following activation, MMP-9 can be transformed into type IV collagenase, which degrades and destroys 

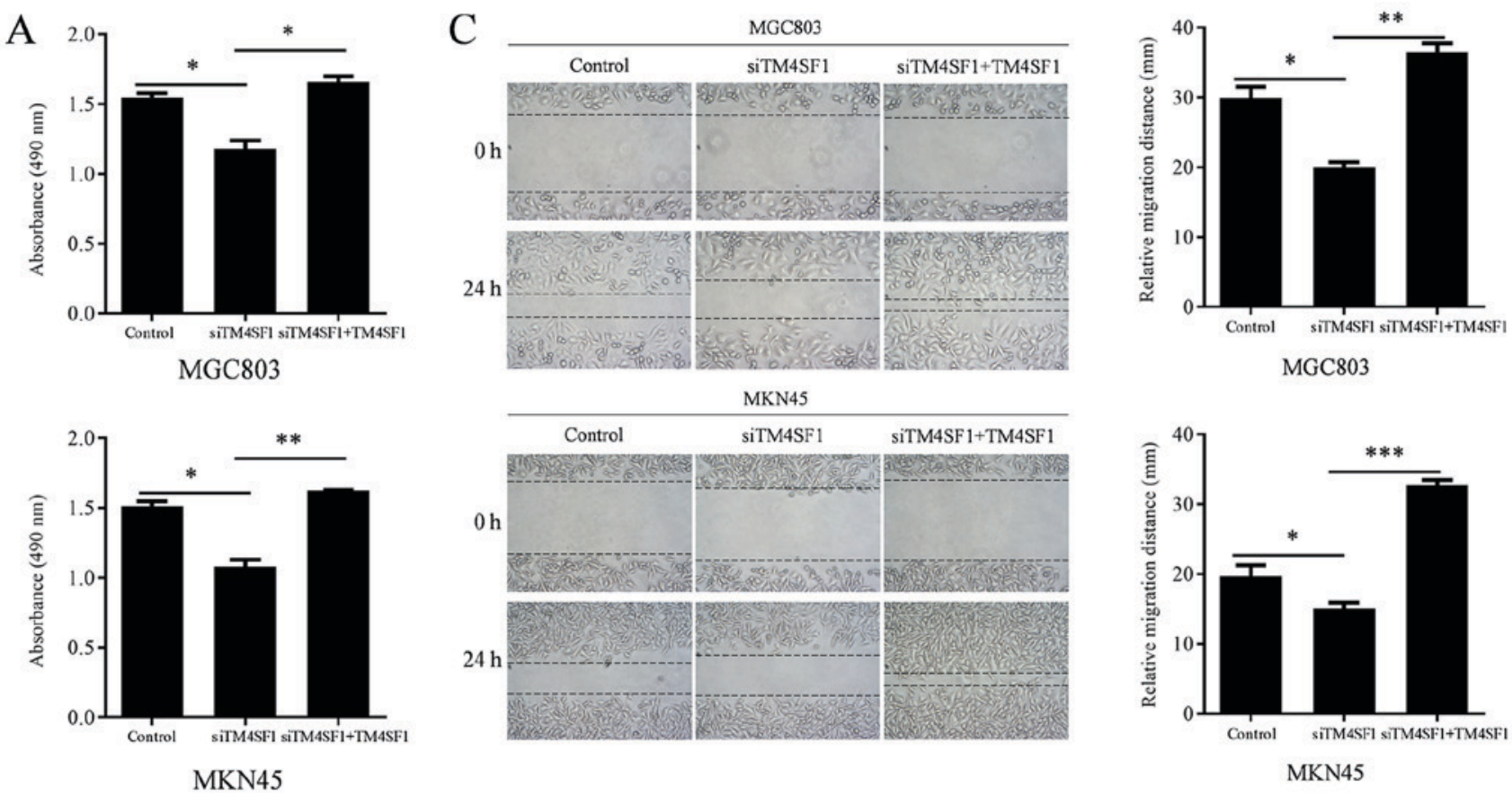

B
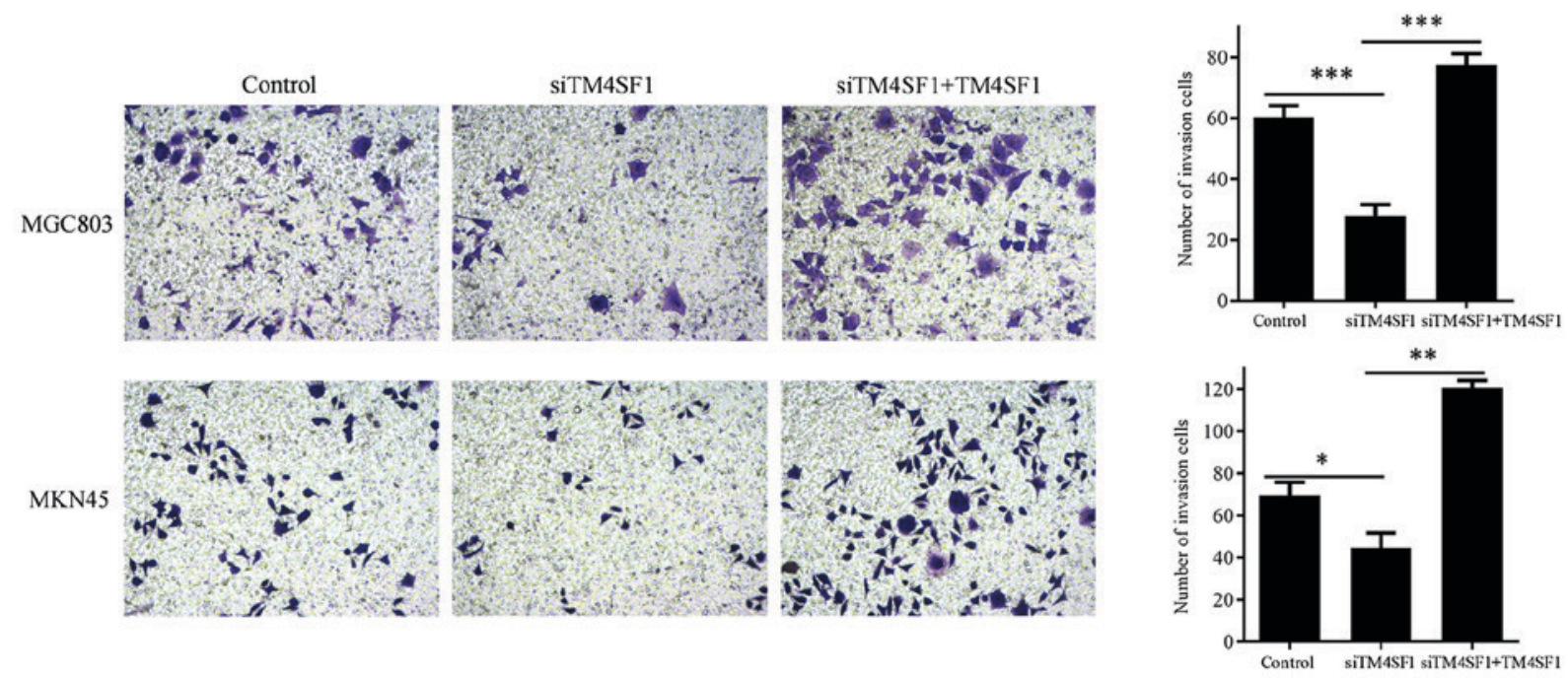

Figure 4. The role of TM4SF1 in the proliferation, migration and invasion of gastric cancer cells. (A) TM4SF1 knockdown reduced GC cell proliferation, while TM4SF1 upregulation increased GC cell proliferation. (B) TM4SF1 knockdown reduced GC cell invasion, while TM4SF1 upregulation increased GC cell invasion. (C) TM4SF1 knockdown resulted in reduced GC cell migration, while TM4SF1 upregulation increased GC cell migration. Each column is presented as the means of three separate experiments. ${ }^{*} \mathrm{P}<0.05,{ }^{* *} \mathrm{P}<0.01$ and ${ }^{* * * *} \mathrm{P}<0.001$. TM4SF1, transmembrane-4 L6 family member 1 ; siTM4SF1, cells transfected with TM4SF1 siRNA; control, cells transfected with blank vectors; siTM4SF1+TM4SF1, cells transfected with TM4SF1 siRNA and the TM4SF1-expressing plasmid.

type IV and V collagens as well as gelatin in the extracellular matrix around the tumor surface. Tumor cells are then able to infiltrate the surrounding tissue via the deficient basement membrane, which ultimately results in tumor invasion and metastasis (39).

The present study was not without limitations. Firstly, experiments were only conducted in vitro. Secondly, further research is required to identify the signaling pathways activated by TM4SF1 in GC. Despite these limitations, the results of the present study indicated that TM4SF1 is an anti-apoptotic protein that has the ability to promote the proliferation, migration and invasion of GC cells.

To conclude, the results of the present study indicated that TM4SF1 may serve an important role in the progression of GC. In the future, TM4SF1 may be considered as a novel therapeutic target of GC; however, future in vivo experiments and clinical trials are required.

\section{Acknowledgements}

Not applicable.

\section{Funding}

The present study was supported by the Public Welfare Research Project of Huzhou Science and Technology Bureau (grant no. 2017GY47), Zhejiang Public Welfare Technology Research Social Development Project (grant no. 2014C33137) 
and Huzhou General scientific research project (grant no. 2010YSB08).

\section{Availability of data and materials}

All data that were generated or analyzed in this study are included in this manuscript.

\section{Authors' contributions}

YW conceived and designed the study. XS was a major contributor in writing the manuscript. XS and LL conducted the majority of the experiments. GC performed the statistical analysis. XC cultured the cells and drew the figures. YW conducted the data interpretation. HS performed the literature search and cell transfection. All authors read and approved the manuscript.

\section{Ethics approval and consent to participate}

Not applicable.

\section{Patient consent for publication}

Not applicable.

\section{Competing interests}

The authors declare that they have no competing interests.

\section{References}

1. Siegel RL, Miller KD and Jemal A: Cancer statistics, 2017. CA Cancer J Clin 67: 7-30, 2017.

2. Chen W, Zheng R, Baade PD, Zhang S, Zeng H, Bray F, Jemal A, Yu XQ and He J: Cancer statistics in China, 2015. CA Cancer J Clin 66: 115-132, 2016.

3. Lang GD and Konda VJ: Early diagnosis and management of esophageal and gastric cancer. Minerva Gastroenterol Dietol 59: 357-376, 2013.

4. Li SC, Lee CH, Hung CL, Wu JC and Chen JH: Surgical resection of metachronous hepatic metastases from gastric cancer improves long-term survival: A population-based study. PLoS One 12: e0182255, 2017.

5. Kang JM, Park S, Kim SJ, Kim H, Lee B, Kim J, Park J, Kim ST, Yang HK, Kim WH and Kim SJ: KIAA1324 suppresses gastric cancer progression by inhibiting the oncoprotein GRP78. Cancer Res 75: 3087-3097, 2015.

6. $\mathrm{Ng} \mathrm{J}$ and Lee P: The role of radiotherapy in localized esophageal and gastric cancer. Hematol Oncol Clin North Am 31: 453-468, 2017.

7. Wright MD, Ni J and Rudy GB: The L6 membrane proteins-a new four-transmembrane superfamily. Protein Sci 9: 1594-1600, 2000.

8. Shih SC, Zukauskas A, Li D, Liu G, Ang LH, Nagy JA, Brown LF and Dvorak HF: The L6 protein TM4SF1 is critical for endothelial cell function and tumor angiogenesis. Cancer Res 69: 3272-3277, 2009.

9. Zukauskas A, Merley A, Li D, Ang LH, Sciuto TE, Salman S, Dvorak AM, Dvorak HF and Jaminet SC: TM4SF1: A tetraspanin-like protein necessary for nanopodia formation and endothelial cell migration. Angiogenesis 14: 345-354, 2011.

10. Cao J, Yang JC, Ramachandran V, Arumugam T, Deng DF, Li ZS, Xu LM and Logsdon CD: TM4SF1 regulates pancreatic cancer migration and invasion in vitro and in vivo. Cell Physiol Biochem 39: 740-750, 2016.

11. Huang YK, Fan XG and Qiu F: TM4SF1 promotes proliferation, invasion, and metastasis in human liver cancer cells. Int J Mol Sci 17: E661, 2016.
12. Sun Y, Xu Y, Xu J, Lu D and Wang J: Role of TM4SF1 in regulating breast cancer cell migration and apoptosis through PI3K/AKT/mTOR pathway. Int J Clin Exp Pathol 8: 9081-9088, 2015.

13. Kaneko R, Tsuji N, Kamagata C, Endoh T, Nakamura M, Kobayashi D, Yagihashi A and Watanabe N: Amount of expression of the tumor-associated antigen L6 gene and transmembrane 4 superfamily member 5 gene in gastric cancers and gastric mucosa. Am J Gastroenterol 96: 3457-3458, 2001.

14. Ke J, Ma P, Chen J, Qin J and Qian H: Lgr6 promotes the progression of gastric cancer through PI3K/AKT/mTOR pathway. Onco Targets Ther 11: 3025-3033, 2018.

15. Mahdavinezhad A, Yadegarazari R, Mousavi-Bahar SH, Poorolajal J, Jafari M, Amirzargar MA, Effatpanah H and Saidijam M: Evaluation of zinc finger E-box binding homeobox 1 and transforming growth factor-beta 2 expression in bladder cancer tissue in comparison with healthy adjacent tissue. Investig Clin Urol 58: 140-145, 2017

16. Li L, Jiang X, Zhang Q, Dong X, Gao Y, He Y, Qiao H, Xie F, $X$ ie $X$ and Sun $X$ : Neuropilin-1 is associated with clinicopathology of gastric cancer and contributes to cell proliferation and migration as multifunctional co-receptors. J Exp Clin Cancer Res 35: 16, 2016.

17. Yang M, Gu YY, Peng H, Zhao M, Wang J, Huang SK, Yuan XH, Li J, Sang JL, Luo Q and Huang C: NAIF1 inhibits gastric cancer cells migration and invasion via the MAPK pathways. J Cancer Res Clin Oncol 141: 1037-1047, 2015.

18. Livak KJ and Schmittgen TD: Analysis of relative gene expression data using real-time quantitative PCR and the 2(-Delta Delta $\mathrm{C}(\mathrm{T}))$ method. Methods 25: 402-408, 2001

19. Schneider CA, Rasband WS and Eliceiri KW: NIH image to ImageJ: 25 years of image analysis. Nat Methods 9: 671-675, 2012.

20. Shaik AB, Rao GK, Kumar GB, Patel N, Reddy VS, Khan I, Routhu SR, Kumar CG, Veena I, Chandra Shekar K, et al: Design, synthesis and biological evaluation of novel pyrazolochalcones as potential modulators of PI3K/Akt/mTOR pathway and inducers of apoptosis in breast cancer cells. Eur J Med Chem 139: 305-324, 2017

21. Zhao KH, Zhang C, Bai Y, Li Y, Kang X, Chen JX, Yao K, Jiang T, Zhong XS and Li WB: Antiglioma effects of cytarabine on leptomeningeal metastasis of high-grade glioma by targeting the PI3K/Akt/mTOR pathway. Drug Des Devel Ther 11: 1905-1915, 2017.

22. Lin YT, Wang HC, Hsu YC, Cho CL, Yang MY and Chien CY: Capsaicin induces autophagy and apoptosis in human nasopharyngeal carcinoma cells by downregulating the PI3K/AKT/mTOR pathway. Int J Mol Sci 18: E1343, 2017.

23. Wen R, Hu S, Xiao Q, Han C, Gan C, Gou H, Liu H, Li L, Xu H, $\mathrm{He} \mathrm{H}$ and Wang J: Leptin exerts proliferative and anti-apoptotic effects on goose granulosa cells through the PI3K/Akt/mTOR signaling pathway. J Steroid Biochem Mol Biol 149: 70-79, 2015.

24. Ugarte-Uribe B and García-Sáez AJ: Apoptotic foci at mitochondria: In and around Bax pores. Philos Trans R Soc Lond Biol Sci 372: 20160217, 2017.

25. Henshall DC, Araki T, Schindler CK, Lan JQ, Tiekoter KL, Taki W and Simon RP: Activation of Bcl-2-associated death protein and counter-response of Akt within cell populations during seizure-induced neuronal death. J Neurosci 22: 8458-8465, 2002.

26. Hashimoto S, Setareh M, Ochs RL and Lotz M: Fas/Fas ligand expression and induction of apoptosis in chondrocytes. Arthritis Rheum 40: 1749-1755, 1997.

27. Lekishvili T, Fromm E, Mujoomdar M and Berditchevski F: The tumour-associated antigen L6 (L6-Ag) is recruited to the tetraspanin-enriched microdomains: Implication for tumour cell motility. J Cell Sci 121: 685-694, 2008.

28. Mantegazza AR, Barrio MM, Moutel S, Bover L, Weck M, Brossart P, Teillaud JL and Mordoh J: CD63 tetraspanin slows down cell migration and translocates to the endosomal-lysosomal-MIICs route after extracellular stimuli in human immature dendritic cells. Blood 104: 1183-1190, 2004.

29. He B, Liu L, Cook GA, Grgurevich S, Jennings LK and Zhang XA: Tetraspanin CD82 attenuates cellular morphogenesis through down-regulating integrin alpha6-mediated cell adhesion. J Biol Chem 280: 3346-3354, 2005. 
30. Zhang XA, He B, Zhou B and Liu L: Requirement of the p130CAS-Crk coupling for metastasis suppressor KAI1/CD82-mediated inhibition of cell migration. J Biol Chem 278: 27319-27328, 2003.

31. Chang YW, Chen SC, Cheng EC, Ko YP, Lin YC, Kao YR, Tsay YG, Yang PC, Wu CW and Roffler SR: CD13 (aminopeptidase N) can associate with tumor-associated antigen L6 and enhance the motility of human lung cancer cells. Int J Cancer 116 : 243-252, 2005

32. Allioli N, Vincent S, Vlaeminck-Guillem V, DecaussinPetrucci M, Ragage F, Ruffion A and Samarut J: TM4SF1, a novel primary androgen receptor target gene over-expressed in human prostate cancer and involved in cell migration. Prostate 71: 1239-1250, 2011.

33. Yuan Y, Jiang YC, Sun CK and Chen QM: Role of the tumor microenvironment in tumor progression and the clinical applications (Review). Oncol Rep 35: 2499-2515, 2016.

34. Xue L, Yu X, Jiang X, Deng X, Mao L, Guo L, Fan J, Fan Q, Wang L and Lu SH: TM4SF1 promotes the self-renewal of esophageal cancer stem-like cells and is regulated by miR-141. Oncotarget 8: 19274-19284, 2017.
35. Lin CI, Merley A, Sciuto TE, Li D, Dvorak AM, Melero-Martin JM, Dvorak HF and Jaminet SC: TM4SF1: A new vascular therapeutic target in cancer. Angiogenesis 17: 897-907, 2014

36. Mitsutake N, Iwao A, Nagai K, Namba H, Ohtsuru A, Saenko V and Yamashita S: Characterization of side population in thyroid cancer cell lines: Cancer stem-like cells are enriched partly but not exclusively. Endocrinology 148: 1797-1803, 2007.

37. Bae S, Shim SH, Park CW, Son HK, Lee HJ, Son JY, Jeon C and $\mathrm{Kim} \mathrm{H}$ : Combined omics analysis identifies transmembrane 4 L6 family member 1 as a surface protein marker specific to human mesenchymal stem cells. Stem Cells Dev 20: 197-203, 2011.

38. Leppä S, Saarto T, Vehmanen L, Blomqvist C and Elomaa I: A high serum matrix metalloproteinase-2 level is associated with an adverse prognosis in node-positive breast carcinoma. Clin Cancer Res 10: 1057-1063, 2004.

39. Ravikumar TS, Steele G Jr, Kane R and King V: Experimental and clinical observations on hepatic cryosurgery for colorectal metastases. Cancer Res 51: 6323-6327, 1991. 